\title{
Restless Genital Syndrome: A Rare Case Series of Four Patients and a Literature Review
}

\author{
Hye-Rim Shin, MSc, $M^{1 *}$, Sun Jung Han, MSc, MD ${ }^{2 *}$, Ki-Young Jung, MD, PhD ${ }^{3,4,5}$ \\ ${ }^{1}$ Department of Neurology, Dankook University Hospital, Cheonan, Chungnam, Korea \\ 2Inam Neuroscience Research Center, Department of Neurology, Wonkwang University Sanbon Hospital, Wonkwang University School of Medicine, \\ Gunpo, Korea \\ ${ }^{3}$ Department of Neurology, Seoul National University Hospital, Seoul National University College of Medicine, Seoul, Korea \\ ${ }^{4}$ Sensory Organ Research Institute, Seoul National University Medical Research Center, Seoul, Korea \\ ${ }^{5}$ Neuroscience Research Institute, Seoul National University College of Medicine, Seoul, Korea
}

Received: December 3, 2020

Accepted: December 19, 2020

\section{Correspondence}

Ki-Young Jung, $\mathrm{MD}, \mathrm{PhD}$

Department of Neurology,

Seoul National University Hospital,

Seoul National University College of Medicine,

101 Daehak-ro, Jongno-gu, Seoul 03080, Korea

Tel +82-2-2072-4988

Fax +82-2-3672-7553

E-mail jungky@snu.ac.kr

*These authors contributed equally to this work.

ORCID

Hye-Rim Shin

https://orcid.org/0000-0001-5861-2876

Sun Jung Han

https://orcid.org/0000-0001-8622-2349

Ki-Young Jung

https://orcid.org/0000-0001-5528-9081

(C) This is an Open Access article distributed under the terms of the Creative Commons Attribution Non-Commercial License (https://creativecommons.org/licenses/by-nc/4.0) which permits unrestricted non-commercial use, distribution, and reproduction in any medium, provided the original work is properly cited.
Restless genital syndrome (RGS) is a rare disorder with unpleasant sensation in the genital area and unwanted sexual arousal. Only a few cases of RGS have been reported, so we presented four cases of RGS. Four cases were all middle-age female, and was commonly complaint paresthesia on their genital area and unwanted sexual arousal. The typical symptoms of restless legs syndrome (RLS), affecting on their lower extremities were accompanied. RGS is difficult to diagnose because it presents ambiguous sensations that are difficult to describe, along with embarrassment in reporting sexual feelings. Clinicians should be aware of the genital discomfort and sexual arousal that can develop in RLS.

Sleep Med Res 2020;11(2):145-148

Key Words Restless legs syndrome, Dopamine agonists, Pregabalin.

\section{INTRODUCTION}

Restless genital syndrome (RGS) is a rare disorder that presents paresthesia and uncomfortable feelings in the genital area, with restless legs syndrome (RLS) and/or overactive bladder (OAB) syndrome related to the genital symptoms [1,2]. According to the international RLS study group (IRLSSG), RLS is diagnosed by five diagnostic criteria: urge to move, worse at rest, relief by movement, worse at evening or night, and not explained by other medical or behavioral problem [3]. The RLS typically affects lower extremities, but there are several reports of RLS affecting another body parts, such as the bladder and abdomen [4-6]. Among the RGS patients, the sensory symptoms were similar to those of RLS, such as difficulty describing the abnormal sensation and an urge to rub the genital area $[1,2]$. Therefore, RGS is thought to be atypical RLS presenting sensory symptoms in the genital area $[1,2,4]$.

However, there has been only a few case reports of RGS thus far [2,7-9]. Here, we present cases of RGS that were treated successfully with management as RLS (Table 1).

\section{CASE REPORT}

\section{Case 1}

A 61-year-old female presented to the sleep clinic with discomfort in her legs and lower abdomen for 11 years. She felt an urge to move her legs, a creeping and restless sensation on her legs, and sometimes also felt a squeezing and rising sensation in her lower abdomen. The symptoms started when she would go to sleep and were temporarily relieved when she moved her legs. 
Table 1. Patient characteristics and RGS

\begin{tabular}{|c|c|c|c|c|c|c|c|c|c|}
\hline $\begin{array}{l}\text { Case } \\
\text { number }\end{array}$ & Sex/age & $\begin{array}{l}\text { Past medical } \\
\text { history }\end{array}$ & $\begin{array}{l}\text { Age of } \\
\text { RLS } \\
\text { onset } \\
\text { (years) }\end{array}$ & $\begin{array}{l}\text { Age of } \\
\text { RGS } \\
\text { onset } \\
\text { (years) }\end{array}$ & Genital sensations & $\begin{array}{l}\text { Baseline } \\
\text { hemoglobin } \\
(\mathrm{g} / \mathrm{dL})\end{array}$ & $\begin{array}{l}\text { Baseline } \\
\text { serum } \\
\text { iron } \\
(\mu \mathrm{g} / \mathrm{dL})\end{array}$ & $\begin{array}{c}\text { Baseline } \\
\text { serum } \\
\text { ferritin } \\
(\mu \mathrm{g} / \mathrm{L})\end{array}$ & $\begin{array}{l}\text { Medical } \\
\text { treatment } \\
\text { of RGS }\end{array}$ \\
\hline 1 & $\mathrm{~F} / 61$ & Hyperlipidemia & 51 & 61 & $\begin{array}{l}\text { Restlessness, squeezing sensation } \\
\text { in the lower abdomen, sexual } \\
\text { impulse }\end{array}$ & 13.0 & 77.0 & 60.7 & $\begin{array}{l}\text { Pramipexole, } \\
\text { pregabalin, } \\
\text { IV iron }\end{array}$ \\
\hline 2 & $\mathrm{~F} / 65$ & $\begin{array}{l}\text { Gallbladder } \\
\text { cancer, carotid } \\
\text { atherosclerosis }\end{array}$ & 30 & 30 & $\begin{array}{l}\text { Tingling, restlessness, sexual } \\
\text { impulse }\end{array}$ & 14.0 & 49.0 & 27.2 & $\begin{array}{l}\text { Ropinirole, } \\
\text { pregabalin, } \\
\text { IV iron }\end{array}$ \\
\hline 3 & $\mathrm{~F} / 51$ & None & 48 & 48 & $\begin{array}{l}\text { Sexual arousal, bloating } \\
\text { sensation in the lower abdomen }\end{array}$ & 13.1 & 49.0 & 85.6 & Pregabalin \\
\hline 4 & $\mathrm{~F} / 50$ & None & 49 & 49 & $\begin{array}{l}\text { Stuffy feeling on her external } \\
\text { genitals and right toe }\end{array}$ & 13.2 & 70.1 & 70.1 & $\begin{array}{l}\text { Ropinirole, } \\
\text { gabapentin }\end{array}$ \\
\hline
\end{tabular}

RLS: restless legs syndrome, RGS: restless genital syndrome, IV: intravenous.

She had endoscopy for abdominal discomfort, and no abnormalities were identified. She underwent knee replacement surgery to improve the paresthesia of her legs, but the symptoms remained. She was then diagnosed with RLS at the local clinic and took ropinirole $1 \mathrm{mg}$ before sleep. However, the discomfort in her legs became worse after the initial improvement and lasted for several months. She had a past medical history of hyperlipidemia and was taking no other medication except ropinirole and lipid-lowering drugs. She had no history of peripheral neuropathy or varicose veins, which can mimic RLS. She had no family history of RLS. Her body mass index (BMI) was $24.24 \mathrm{~kg} / \mathrm{m}^{2}$ $(156 \mathrm{~cm}, 59 \mathrm{~kg})$. Her baseline International Restless Legs Scale (IRLS) score was 19, and RLS-Quality of Life (RLS-QOL) Scale score was 85. Her Pittsburgh Sleep Quality Index (PSQI) was 7, Insomnia Severity Index (ISI) was 3, and Beck's Depression Inventory (BDI) was 14. Her hemoglobin and serum iron levels were in the normal ranges $(13.0 \mathrm{~g} / \mathrm{dL}$ and $77 \mu \mathrm{g} / \mathrm{dL})$, and her ferritin and transferrin saturation were lowered to $60.7 \mu \mathrm{g} / \mathrm{L}$ and $20.8 \%$, respectively. Her brain MRI was within the normal range.

We reduced the dose of ropinirole to $0.5 \mathrm{mg}$ and added pramipexole $0.25 \mathrm{mg}$ at 9 p.m. (two hours before her bedtime). After one month, she felt improvement in her sensory symptoms by $50 \%$. We then discontinued the ropinirole and administered intravenous (IV) iron therapy (ferric carboxymaltose $1000 \mathrm{mg}$ ). The symptoms were much improved for 6 months after IV iron injection. However, after 6 months, her RLS symptoms became worse. She complained of a squeezing sensation in her lower abdomen. Sometimes, she also felt like she had a lump in her stomach, with uprising sensations in her abdomen. She described her feelings as restlessness and weird feelings in the perineal area, with irritating sensations at the knee. Inappropriate sexual impulses had occurred prior to discomfort in the perineal area, but she could not talk frankly. The IRLS had progressed to 30, and the ISI and PSQI had also aggravated to 19 and 10, respectively. The patient received additional IV iron injection, but the symp- toms remained, though follow-up ferritin and transferrin saturation were in the normal ranges $(250.8 \mu \mathrm{g} / \mathrm{L}$ and $47.9 \%$, respectively). We added pregabalin $50 \mathrm{mg}$ at 9 p.m. and then increased the dosage to $75 \mathrm{mg}$ after 5 months. After adding the pregabalin, the symptoms in the legs and genital area were well controlled. However, the symptoms recently became worse again after reducing the dose of pregabalin to $50 \mathrm{mg}$.

\section{Case 2}

A 65-year-old female visited the sleep clinic complaining of aggravated insomnia after having endoscopic surgery one month ago. She had felt tingling sensations in her genital area and lower abdomen that spread up her trunk for 35 years. Sometimes she felt tingling sensations and restlessness on her thigh, but the symptoms were improved after taking a walk. The symptoms were aggravated at resting and at night and sometimes also occurred after overeating dinner. She reported that she had problems falling asleep because of the uncomfortable feelings in her groin and thigh.

She had a past medical history of gallbladder cancer, for which she had surgery one month ago. She was taking aspirin and statin for carotid atherosclerosis and painkillers for arthritis. She had no other medical history of RLS mimics and did not take antidepressants or dopamine antagonists that could cause RLS. She had no family history of RLS. Her BMI was $16.44 \mathrm{~kg} / \mathrm{m}^{2}(148 \mathrm{~cm}$, $36 \mathrm{~kg}$ ). Her baseline IRLS was 33, and her RLS-QOL Scale score was 37.5. Her PSQI was 13, ISI was 21, and BDI was 27. Her hemoglobin was in the normal range $(14.0 \mathrm{~g} / \mathrm{dL})$, and serum iron was slightly reduced to $49 \mu \mathrm{g} / \mathrm{dL}$. Her ferritin and transferrin saturation were significantly reduced to $27.2 \mu \mathrm{g} / \mathrm{L}$ and $16.4 \%$, respectively.

Ropinirole $0.25 \mathrm{mg}$ before sleep was ineffective. IV iron (ferric carboxymaltose $1000 \mathrm{mg}$ ) was injected, and her ferritin level increased to $717.5 \mu \mathrm{g} / \mathrm{L}$. Her symptoms began to improve 4 weeks after IV iron therapy. Her IRLS was lowered to 20, and ISI and 
PSQI improved to 17 and 7, respectively.

After 9 months, the tingling sensation had expanded to her trunk and shoulder, and the abnormal sensation also occurred in the afternoon and evening. The dysesthesia of her thigh and perineal area was aggravated when she stayed still, such as when watching movies for several hours. We suspected augmentation of RLS and recommended that she take pregabalin at 5 p.m. However, the tingling sensation of the thigh and perineal area in the afternoon remained. Therefore, we changed the schedule of pregabalin from 5 p.m. to 3:30 p.m. and added additional pregabalin $75 \mathrm{mg}$ before sleep. Her ferritin and transferrin saturation were reduced to $49.0 \mu \mathrm{g} / \mathrm{L}$ and $27.2 \%$, respectively. The patient received additional IV iron, after which her symptoms markedly improved, and her ferritin level increased to $235.2 \mu \mathrm{g} / \mathrm{L}$. Her IRLS was improved to 14, and ISI and PSQI also improved to 11. The medications have been maintained, and the tingling sensation on her perineal area has been well-controlled thus far.

\section{Case 3}

A 51-year-old female visited the sleep clinic complaining of a tingling sense and restlessness on her thigh and leg that was aggravated at resting for 2.5 years. She also complained of a bloating sensation in her lower abdomen and sexual arousal without voluntary sexual desire. The sexual arousal and impulse increased especially when she had restlessness and discomfort in her lower extremities. She had no past medical history and was taking duloxetine and alprazolam from a local clinic to control the discomfort in her abdomen and lower extremities. She had no family history of RLS. Her hemoglobin, serum iron, and ferritin were in the normal ranges ( $13.1 \mathrm{~g} / \mathrm{dL}, 49 \mu \mathrm{g} / \mathrm{dL}$, and $85.6 \mu \mathrm{g} / \mathrm{L}$, respectively).

We prescribed pregabalin $50 \mathrm{mg}$ before sleep and recommended that she discontinue duloxetine, which may aggravate the RLS symptoms. The sensory symptoms nearly disappeared after she began taking pregabalin, but she complained of dizziness. We reduced the dosage of pregabalin to $25 \mathrm{mg}$, and the symptoms were well-controlled even after reducing the dosage.

\section{Case 4}

A 50-year-old female visited the sleep clinic complaining of stuffy feeling on her external genitals and right toe with increased sexual impulse. She also had urge to move her right toe, which was aggravated at night or at resting. The unwanted sexual desire did not resolve after having intercourse, but transiently improved during she walks around. The symptoms first started when she was a teenager. Previously she had stuffy feelings on her knee, but the symptoms migrated to clitoris and right toe for one year. She had no past medical history and was not taking any medications. She had family history of RLS, including grandmother, father, and aunt. Her hemoglobin, serum iron, and ferritin were in the normal ranges $(13.2 \mathrm{~g} / \mathrm{dL}, 70.1 \mu \mathrm{g} / \mathrm{dL}$, and $70.1 \mu \mathrm{g} / \mathrm{L}$, respectively).

Ropinirole $0.5 \mathrm{mg}$ and gabapentin $300 \mathrm{mg}$ before sleep were given with considerable efficacy.

\section{DISCUSSION}

We present four cases of RGS who developed genital discomfort and unwanted sexual arousal after typical symptoms of RLS presented. All patients met the diagnostic criteria of the International IRLSSG: urge to move, worse at rest, relief by activity, worse at night, and exclusion of other medical/behavioral conditions [3], and their genital sensory symptoms were similar to symptoms experienced in the lower extremities in typical RLS. The patients felt the urge to touch and rub, which was relieved by movements, and the symptoms got worse at night or when resting. The genital discomfort and unwanted sexual arousal were both well-controlled by dopamine agonist, IV iron, and $\alpha 2-\delta$ ligands (pregabalin), which are commonly used to improve RLS symptoms.

RGS is a rare disorder presenting RLS-like sensory symptoms in the genital area and unwanted sexual arousal without voluntary sexual desire [1,2]. RGS is difficult to diagnose because patients have difficulty describing their sensory symptoms and may feel embarrassed to report their sexual arousal and desire to clinicians $[1,2]$, as in our cases.

The pathologic mechanism of RGS is not clearly understood. In previous studies, vascular dysfunction, such as microvascular arteriovenous shunt [10], and small fiber neuropathy [2,7] were suggested as possible mechanisms of RGS. However, the mechanism of RGS is not well understood. Dysfunction of the sympathetic nervous system and vascular abnormalities may be related to the pathogenesis of RGS $[1,10]$.

Most of the previous cases reported treatment of RGS only with dopamine agonists $[1,4,8]$. However, this is the first reported treatment of RGS with IV iron (cases 1 and 2). This suggests that RGS shares common mechanism of iron metabolism with typical RLS. Further studies on the pathologic mechanism of RGS should be performed, including examinations of the iron metabolism. In addition, all of the cases experienced paresthesia in their lower extremities before the genital symptoms occurred. This suggests that RGS is an atypical presentation of RLS, and patients with typical RLS could develop the symptoms of RGS.

In our cases, all patients were middle-aged female. This corresponds to previous studies, which reported the median age of RGS as 55 years and indicated that the disorder was more common in female [1,2]. We diagnosed rare cases of RGS with thorough history taking and work-up for RLS. The patients were effectively treated with the same medications as used with RLS. Clinicians should be aware that restlessness and dysesthesia could also occur in the genital area in patients with RLS.

\section{Ethical Policy}

This study followed the principles of the Declaration of Hel- 
sinki, and was approved by the Seoul National University Hospital (2006-208-1137) and Wonkwang University Hospital (WMCSB202007-57) Institutional Review Board. All information of patients was sufficiently anonymized.

\section{Acknowledgments}

This work was supported by a National Research Foundation (NRF) grant funded by the Korean government (MSIP) (2017R1A2B2012280).

\section{Conflicts of Interest}

The authors have no financial conflicts of interest.

\section{Authors' Contribution}

Conceptualization: Jung KY, Han SJ. Data curation: Jung KY, Han SJ. Formal analysis: Shin HR, Jung KY. Funding acquisition: Jung KY. Methodology: Shin HR, Jung KY. Project administration: Shin HR, Jung KY. Resources: Jung KY, Han SJ. Supervision: Jung KY. Validation: Jung KY. Visualization: Jung KY, Shin HR. Writing-original draft: Shin HR, Han SJ. Writing_review \& editing: all authors.

\section{REFERENCES}

1. Waldinger MD, Schweitzer DH. Persistent genital arousal disorder in 18 Dutch women: Part II. A syndrome clustered with restless legs and overactive bladder. J Sex Med 2009;6:482-97.

2. Waldinger MD, Venema PL, van Gils AP, Schweitzer DH. New insights into restless genital syndrome: static mechanical hyperesthesia and neuropathy of the nervus dorsalis clitoridis. J Sex Med 2009;6: 2778-87.

3. Allen RP, Picchietti DL, Garcia-Borreguero D, Ondo WG, Walters AS, Winkelman JW, et al. Restless legs syndrome/Willis-Ekbom disease diagnostic criteria: updated International Restless Legs Syndrome Study Group (IRLSSG) consensus criteria--history, rationale, description, and significance. Sleep Med 2014;15:860-73.

4. Turrini A, Raggi A, Calandra-Buonaura G, Martinelli P, Ferri R, Provini F. Not only limbs in atypical restless legs syndrome. Sleep Med Rev 2018;38:50-5.

5. Antelmi E, Coccagna G, Ferini-Strambi L, Marelli S, Provini F. 'Restless bladder' and the boundaries of the restless legs syndrome. Eur J Neurol 2013;20:e128.

6. Wang XX, Zhu XY, Wang Z, Dong JW, Ondo WG, Wu YC. Restless abdomen: a spectrum or a phenotype variant of restless legs syndrome? BMC Neurol 2020;20:298.

7. Waldinger MD, Venema PL, van Gils AP, de Lint GJ, Schweitzer DH. Stronger evidence for small fiber sensory neuropathy in restless genital syndrome: two case reports in males. J Sex Med 2011;8:325-30.

8. Sforza E, Hupin D, Roche F. Restless genital syndrome: differential diagnosis and treatment with pramipexole. J Clin Sleep Med 2017;13: 1109-10.

9. Ünsal MA, Doğan T. Is it really rare? Restless genital syndrome. Arch Neuropsychiatry 2020 Jan 23 [Epub]. https://doi.org/10.29399/npa.24950.

10. Markos AR, Dinsmore W. Persistent genital arousal and restless genitalia: sexual dysfunction or subtype of vulvodynia? Int J STD AIDS 2013; 24:852-8. 